\title{
Second-line therapy in elderly patients with advanced nonsmall cell lung cancer
}

\author{
Elisabeth Quoix ${ }^{1}$, Virginie Westeel ${ }^{2}$, Lionel Moreau ${ }^{3}$, Eric Pichon ${ }^{4}$, \\ Armelle Lavolé ${ }^{5}$, Jérome Dauba ${ }^{6}$, Didier Debieuvre ${ }^{7}$, Pierre Jean Souquet ${ }^{8}$, \\ Laurence Bigay-Game ${ }^{9}$, Eric Dansin ${ }^{10}$, Michel Poudenx ${ }^{11}$, Olivier Molinier ${ }^{12}$, \\ Fabien Vaylet ${ }^{13}$, Denis Moro-Sibilot ${ }^{14}$, Denis Herman ${ }^{15}$, Helene Sennelart ${ }^{16}$, \\ Jean Tredaniel ${ }^{17}$, Bertrand Mennecier ${ }^{1}$, Franck Morin ${ }^{18}$, Laurence Baudrin ${ }^{18}$, \\ Bernard Milleron ${ }^{18}$ and Gérard Zalcman ${ }^{18,19}$ on behalf of Intergroupe \\ Francophone de Cancérologie Thoracique
}

\begin{abstract}
Affiliations: 'Dept of Pulmonology, CHU Strasbourg. Strasbourg, ${ }^{2}$ Dept of Pulmonology CHU Besançon, Besançon, ${ }^{3}$ Dept of Pulmonology, CHG, Colmar, ${ }^{4}$ Dept of Pulmonology, CHU, Tours, ${ }^{5}$ Dept of Pulmonology, Tenon Hospital, Paris, ${ }^{6}$ Dept of Medical Oncology, CHG, Mont de Marsan, ${ }^{7}$ Dept of Pulmonology, CHG, Mulhouse, ${ }^{8}$ Dept of Pulmonology, CHU, Pierre-Bénite, ${ }^{9}$ Dept of Pulmonology, Larrey Hospital, Toulouse, ${ }^{10}$ Dept of Medical Oncology, CLCC Oscar Lambret, Lille, ${ }^{11}$ Dept of Medical Oncology, CLCC Antoine Lacassagne, Nice, ${ }^{12}$ Dept of Pulmonology, CHG, Le Mans, ${ }^{13}$ Dept of Pulmonology, Instruction Hospital of the Armies, PercyClamart, ${ }^{14}$ Dept of Pulmonology, CHU La Tronche, Grenoble, ${ }^{15}$ Dept of Pulmonology, CHG, Nevers, ${ }^{16}$ Dept of Medical Oncology, CLCC René Gauducheau, Nantes, ${ }^{17}$ Dept of Medical Oncology, St Joseph Hospital, Paris, ${ }^{18}$ IFCT, Paris, and ${ }^{19}$ Dept of Pulmonology and Thoracic Oncology, CHU, Caen, France.
\end{abstract}

Correspondence: E Quoix, Dept of Pneumology, University Hospital, 1 Place de l'hôpital, F-67091 Strasbourg Cedex, France. E-mail: elisabeth.quoix@chru-strasbourg.fr

ABSTRACT There is no dedicated study on second-line treatment for elderly patients with advanced nonsmall cell lung cancer (NSCLC). We report the results on second-line erlotinib therapy from our previously published phase III study comparing single-agent therapy with platinum-based doublet (carboplatin plus paclitaxel) therapy in 451elderly patients.

Erlotinib was given to patients exhibiting disease progression or experiencing excessive toxicity during first-line therapy, until further progression or unacceptable toxicity.

In total, $292(64.7 \%)$ patients received erlotinib as second-line therapy. Initial performance status 0-1, stage IV NSCLC and an Activities of Daily Living score of 6 were independent factors for receiving erlotinib. Median (95\% CI) overall survival was 4 (3.2-6.7) versus 6.8 (5.0-8.3) months in the single-agent and doublet arms, respectively $(\mathrm{p}=0.089)$. Performance status $0-1$, never having smoked, adenocarcinoma and weight loss $\leqslant 5 \%$ were favourable independent prognostic factors of survival, whereas the randomisation arm had no significant impact. Among the 292 patients who received erlotinib, 60 (20.5\%) experienced grade 3-4 toxic effects, the most frequent being rash.

Erlotinib as second-line therapy is feasible, leading to efficacy results similar to those obtained in a previous randomised study that was not dedicated to elderly patients, with acceptable toxicity.

@ERSpublications

Erlotinib is a feasible second-line therapy in elderly patients with advanced nonsmall cell carcinoma http://ow.ly/pz6ud

This article has supplementary material available from www.erj.ersjournals.com

Received: March 182013 | Accepted after revision: June 172013 | First published online: Oct 102013

Clinical trial: This study is registered at www.clinicaltrials.gov with identifier number NCT00298415.

Support statement: This work was supported by the Institut National du Cancer, the French Ligue Nationale Contre le Cancer, and by grants from Bristol Myers Squibb, Pierre Fabre and Roche.

Conflict of interest: Disclosures can be found alongside the online version of this article at www.erj.ersjournals.com

Copyright @ERS 2014 


\section{Introduction}

There has been a notable rise in the incidence of lung cancer in elderly patients, with a median age at diagnosis of $\sim 70$ years. This rise reflects increasing life expectancy, increasing risk of developing cancer with age, and perhaps decreasing nihilism among patients and doctors. As documented in younger counterparts, nonsmall cell lung cancer (NSCLC) represents $\sim 85 \%$ of all diagnoses [1] and around two-thirds of patients are diagnosed with advanced disease.

For fit, chemotherapy-naïve, nonelderly patients with advanced NSCLC not amenable to chemoradiotherapy, platinum-based doublets are considered the standard first-line treatment. Single-agent therapy has long been recommended for first-line chemotherapy in elderly patients (aged $\geqslant 70$ years), gemcitabine and vinorelbine being the most frequently studied agents [2]. However, subgroup analyses of several phase III trials, which were not focused on elderly patients, suggested that patients aged $\geqslant 70$ years derived similar benefits from a platinum-based doublet as their younger counterparts [3-5]. In 2006, our group conducted a phase III study comparing single-agent therapy (gemcitabine or vinorelbine according to the centre's choice) to carboplatin and weekly paclitaxel in elderly NSCLC patients [6]. There was considerable benefit derived from the carboplatin-based doublet compared with the single-agent therapy in terms of overall survival. These results led to a modified paradigm of first-line treatment in performance status 0-2 elderly patients with advanced NSCLC, as illustrated by the recently published National Comprehensive Cancer Network recommendations [7].

At the present time, three drugs (docetaxel, pemetrexed and erlotinib) have been authorised for second-line therapy in advanced NSCLC patients, previously treated with at least one line of a platinum-based combination chemotherapy [8-10]. In particular, the BR21 study showed that erlotinib significantly increased overall survival compared with best supportive care for nonselected advanced NSCLC [10]. There have been no randomised trials dedicated to elderly patients with second-line epidermal growth factor receptor (EGFR) tyrosine kinase inhibitors (TKIs). However, subgroup analysis of elderly patients included in the BR21 study showed that there was no differential effect of erlotinib according to age $\geqslant 70$ versus $<70$ years [11]. Due to its good tolerability profile, erlotinib was chosen as systematic second-line therapy in the Intergroupe Francophone de Cancérologie Thoracique (IFCT)0501 trial, after either single-agent or carboplatin-paclitaxel doublet therapy. In this article, we report the mature efficacy and toxicity data pertaining to erlotinib second-line therapy in all-comers aged $\geqslant 70$ years, included in the IFCT0501 phase III trial, who progressed after induction therapy with either a weekly paclitaxel-carboplatin doublet or monotherapy (either gemcitabine or vinorelbine).

\section{Patients and methods}

The protocol was approved by the Ethics Committee of Paris (Paris, France) and the trial was authorised by French Health authorities (NCT00298415). All enrolled patients provided written informed consent.

Details regarding patient selection criteria were provided in the first publication from the current study [6]. Briefly, 451 patients were enrolled between April 2006 and December 2009 by 61 institutions. The main eligibility criteria were: 1 ) locally advanced NSCLC with contraindication to radiation therapy or stage IV disease; 2) age between 70 and 89 years; 3 ) performance status $0-2 ; 4)$ adequate haematological, hepatic and renal function; and 5) life expectancy of $\geqslant 12$ weeks. Patients were randomized 1:1 to the two treatment groups using minimisation and stratification by centre for performance status (0-1 versus 2), stage (III versus IV) and age ( $\leqslant 80$ versus $>80$ years). Patients assigned to the single-agent therapy received either vinorelbine or gemcitabine (according to the centre's initial choice), while those assigned to doublet therapy received carboplatin and paclitaxel (fig. 1). A maximum of five cycles were delivered in the single-agent group versus four in the doublet group. For patients exhibiting disease progression at any time during or after induction treatment or for those experiencing excessive toxicity during first-line therapy, treatment

FIGURE 1 Treatment scheme. Doses: vinorelbine $30 \mathrm{mg} \cdot \mathrm{m}^{-2}$, day (D) 1 and 8 , the cycle restarting on $\mathrm{D} 22(\mathrm{D} 1=\mathrm{D} 22)$; gemcitabine $1150 \mathrm{mg} \cdot \mathrm{m}^{-2}, \mathrm{D} 1$ and $8, \mathrm{D} 1=$ D22; carboplatin area under the curve 6, D1, D1=D29; paclitaxel $90 \mathrm{mg} \cdot \mathrm{m}^{-2}, \mathrm{D} 1,8$ and 15. NSCLC: nonsmall cell lung cancer; PS: performance status. \#: institution choice; $"$ : in the case of progressive disease or excessive toxicity.

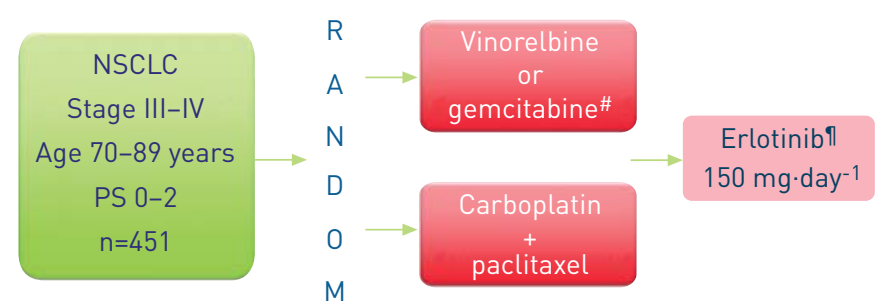


was replaced by erlotinib at $150 \mathrm{mg}$ per day until further progression or unacceptable toxicity. Third-line therapy could be employed at the discretion of the investigators. Baseline disease assessment was performed using chest radiography, thoracic computed tomography, bronchial endoscopy, brain computed tomography or magnetic resonance imaging, and abdominal ultrasonography or computed tomography. EGFR mutational status was not available when the trial was designed (2005) and, therefore, was not systematically recorded for patients undergoing erlotinib second-line therapy. During second-line therapy, disease was assessed using the same imaging procedures every 2 months during the first 6 months, and every 3 months thereafter using the World Health Organization criteria [12]

The current study aimed to describe compliance with second-line erlotinib, median duration of second-line therapy, progression-free survival (PFS), overall survival and prognostic factors, starting from the initiation of erlotinib in the two arms.

Baseline characteristics (at time of randomisation) of patients receiving second-line therapy or not were analysed using logistic regression, for the following factors: first-line treatment arm (monotherapy versus doublet), performance status ( $0-1$ versus 2$)$, weight loss before randomisation ( $\leqslant 5 \%$ versus $>5 \%$ ), body mass index $(\mathrm{BMI})\left(<20,20\right.$ to $\leqslant 26,>26$ to $\leqslant 30$ and $\left.>30 \mathrm{~kg} \cdot \mathrm{m}^{-2}\right)$, age $(\leqslant 80$ versus $>80$ years $)$, smoking status (never- versus ever-smoker), disease stage (III versus IV), histology (adenocarcinoma versus squamous or other), Charlson's comorbidity index score $(\leqslant 2$ versus $>2)$, mini-mental state (MMS) examination score $(\leqslant 23$ versus $>23)$ and activities of daily living $(\mathrm{ADL})$ score $(<6$ versus 6$)$. Variables with a $\mathrm{p}$-value $<0.2$ were included in the multivariate logistic regression and then selected by a backward procedure, with a stay significance level of 0.05 .

Median times on second-line therapy according to the first-line treatment arm were compared using the Mood median test.

Overall survival was defined as the time from first erlotinib administration to death from any cause, or was censored at the last follow-up. PFS was defined as the time from first erlotinib administration to documented disease progression or death, whichever occurred first, or was censored at the last follow-up. The end-point date was April 1, 2012. Cumulative incidence curves for PFS and overall survival were estimated using the Kaplan-Meier method. Median and 1-year overall survival were reported with their respective 95\% confidence intervals, and the medians were compared using the log-rank test. The associations between overall survival and each potential prognostic factor, as shown above, were assessed using the univariate Cox model. As with the logistic regression analysis, variables with a p-value $<0.2$ were included in a multivariate Cox model and then selected by a backward procedure, with a stay significance level of 0.05 .

Fisher's exact test was used to compare grade 3 and 4 toxicity rates during erlotinib therapy between treatment arms.

Analyses were performed on all patients who received at least one dose of erlotinib. Statistical analyses were performed using SAS version 9 (SAS Institute, Cary, NC, USA). A two-sided p-value $<0.05$ was considered to be statistically significant.

\section{Results}

In total, 451 patients were randomly assigned to this study, with 448 receiving at least one injection of firstline therapy. As illustrated in figure 2, of the 444 patients who completed first-line therapy (four patients were still undergoing first-line therapy at the end-point date, three in the doublet and one in the monotherapy arm), 152 (34.2\%) did not continue on with second-line therapy (causes being 78 deaths, 40 general condition deteriorations, 16 protocol violations, seven patient refusals, five consent withdrawals, three major toxicities during first-line therapy precluding any possibility of second-line therapy and three other causes).

Finally, 292 patients received second-line therapy according to protocol. The proportion of patients who actually received second-line erlotinib did not differ between the two arms (144 (63.7\%) out of 226 in the single-agent arm and $148(65.8 \%)$ out of 225 in the doublet arm, p=0.60). Of the 292 patients, four were considered ineligible at baseline assessment (one patient with oxygen dependence, two with other cancer diagnosis within the last 5 years, and one patient with previous chemotherapy and radiation therapy). The reason for undergoing second-line therapy was disease progression for $93.8 \%$ of the 292 patients $(95.1 \%$ in the single-agent arm and $92.6 \%$ in the doublet arm), excessive chemotherapy toxicity for $4.1 \%(2.8 \%$ and $5.4 \%$, respectively) and other reasons in $2.1 \%$ of cases. Baseline characteristics differed greatly between patients who received second-line therapy according to protocol and those who did not, with the former exhibiting significantly better performance status, less weight loss, higher MMS and ADL scores, and a higher proportion of stage IV disease (table 1). Multivariate logistic regression showed that initial 


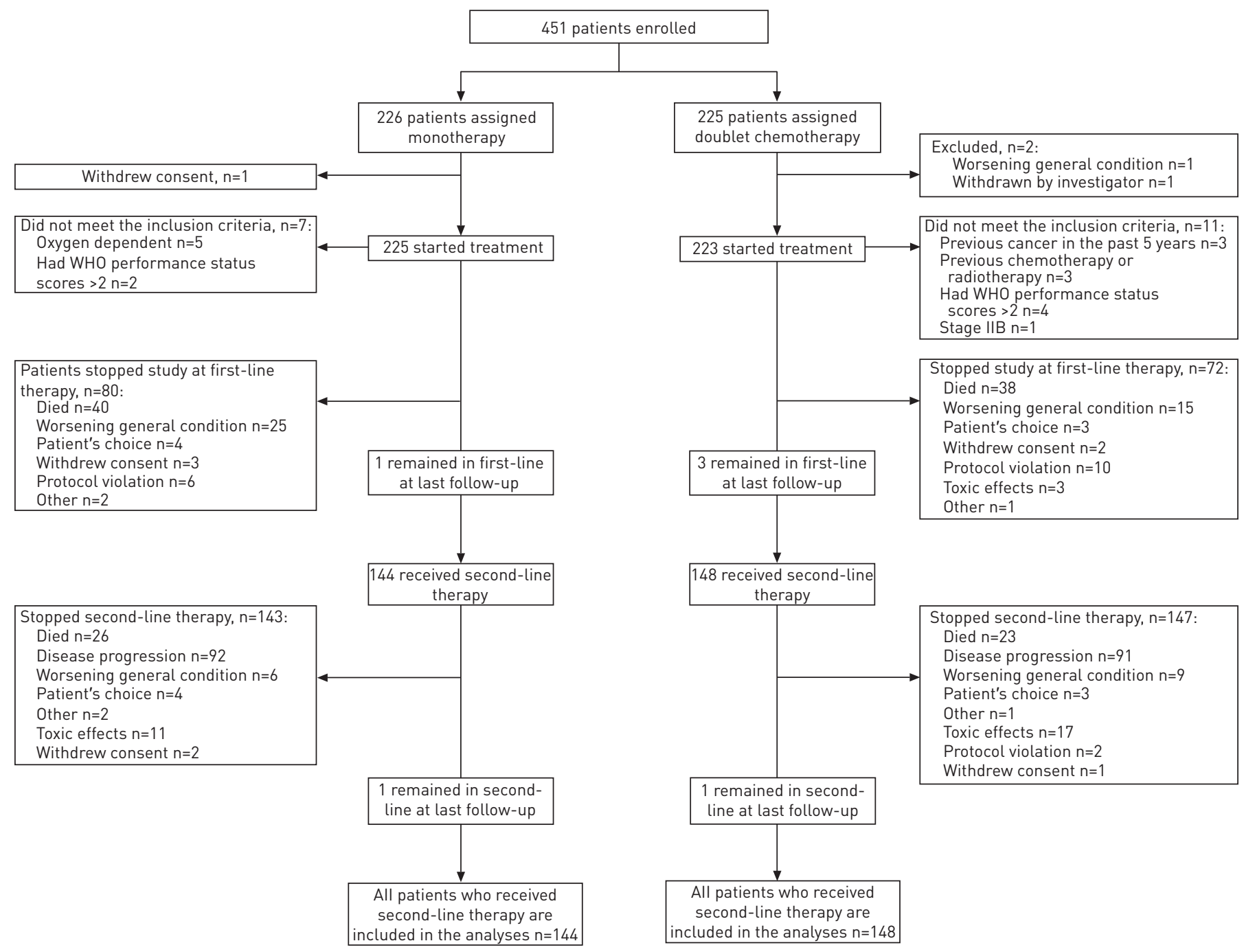

FIGURE 2 Study profile. WHO: World Health Organization.

performance status $0-1$, stage IV disease and ADL score 6 were independent factors for receiving secondline erlotinib therapy.

Of the 292 patients treated with erlotinib, two in the doublet arm were still undergoing treatment at the time of analysis. The reasons for discontinuing erlotinib in the 290 remaining patients are detailed in table 2, with the most common cause being disease progression for both arms (63.1\%). Median (95\% CI) duration of erlotinib treatment was $2.0(1.8-2.3)$ months in the single-agent arm ( $\operatorname{arm} \mathrm{A})$ and $2.2(2.0-2.8)$ months in the doublet arm $(\operatorname{arm~B})(p=0.66)$. In $23.6 \%$ and $25 \%$ of cases, respectively $(p=0.78)$, the erlotinib dose had to be reduced.

PFS from first erlotinib administration was 2.2 (1.9-2.8) months in arm A and 2.6 (2.4-3.0) months in arm B $(\mathrm{p}=0.30)$. Median overall survival (fig. 3) was 4 (3.2-6.7) versus 6.8 (5.0-8.3) months, respectively, $(\mathrm{p}=0.089)$. The 1-year survival rate was $26.4(19.5-33.8)$ and $33.8(26.3-41.4) \%$, respectively $(\mathrm{p}=0.167)$.

Univariate analysis of overall survival since first erlotinib administration according to baseline characteristics is presented in table 3. Performance status 0-1, female sex, never having smoked, adenocarcinoma histology and weight loss $\leqslant 5 \%$ were favourable prognostic factors. Multivariate analysis of overall survival revealed that performance status $0-1$, never having smoked, adenocarcinoma and weight loss $\leqslant 5 \%$ were all favourable independent prognostic factors, whereas the randomisation arm showed no significant impact. We used initial performance status and weight loss, as a substantial number of data were missing at the beginning of second-line therapy ( 83 and 116 out of 292 , respectively). However, survival multivariate analysis performed on the 159 patients without missing data, using the unchanged baseline characteristics but performance status and weight loss registered at the time of second-line therapy, gave 
TABLE 1 Results of univariate and multivariate logistic regression analyses assessing the eligibility to receive erlotinib as second-line therapy (L2) according to baseline patient characteristics (prior to induction therapy)

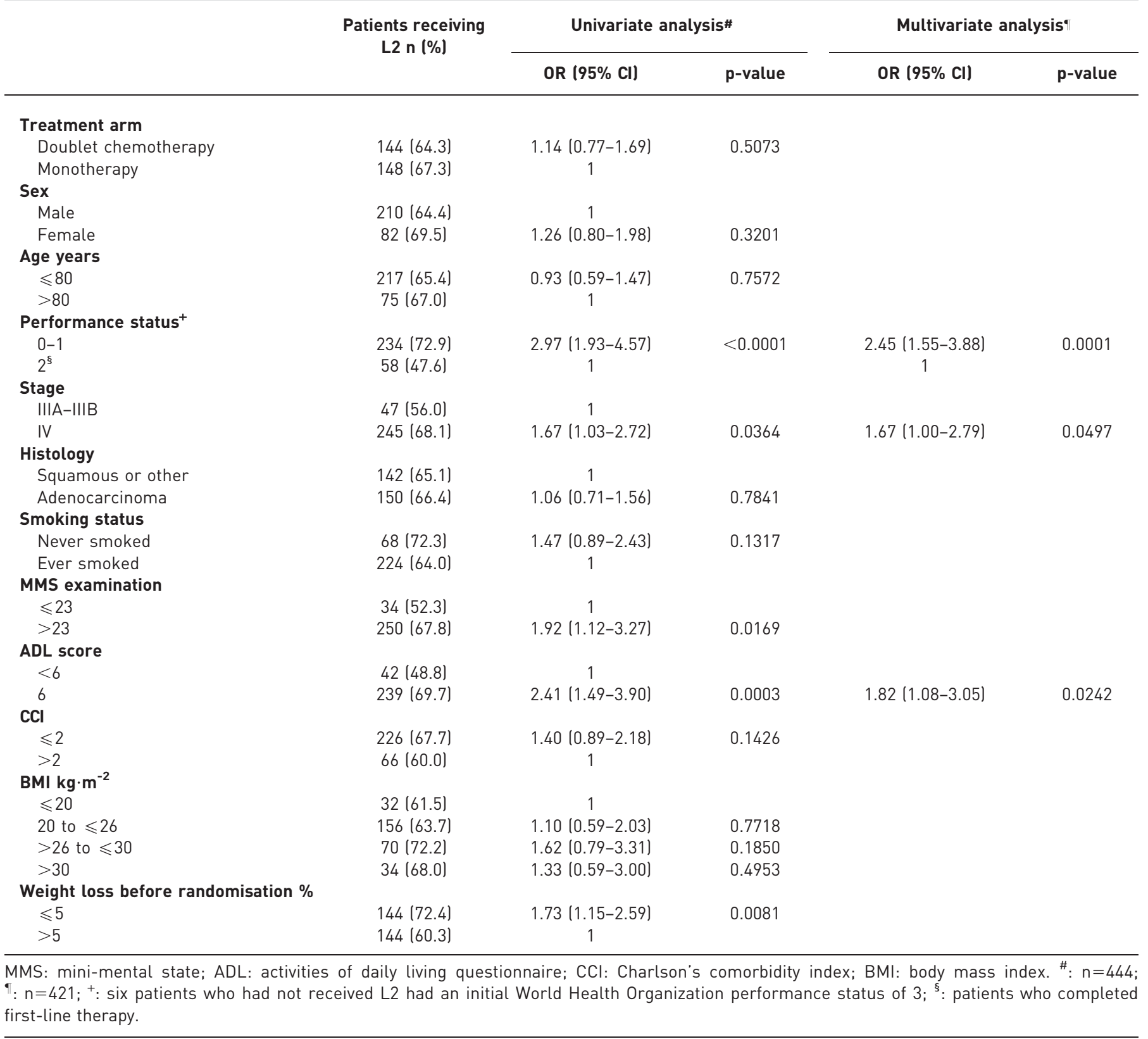

similar results, with performance status $0-1$, weight loss $\leqslant 5 \%$, adenocarcinoma histology still being independent favourable prognostic factors (online supplementary table S1). There was a quantitative interaction between histology and smoking status (interaction test, $\mathrm{p}=0.0013$ ), which remained significant when adjusted for performance status and weight loss (interaction test, $p=0.0011$ ). Indeed, after adjustment, there was highly significant difference in overall survival according to histology for neversmokers, whereas ever-smoker adenocarcinoma patients demonstrated no significantly longer survival rates (fig. 4).

Of the 292 patients who received erlotinib, 60 (20.5\%) experienced grade 3-4 toxic effects (table 4), 28 $(19.4 \%)$ in the single-agent arm and $32(21.6 \%)$ in the doublet arm. The most frequent toxic effects were rash (26 patients), asthenia (12 patients), anorexia (10 patients), and diarrhoea (eight patients), with anorexia significantly more common in the monotherapy group $(\mathrm{p}=0.032)$. Three patients experienced grade 4 toxicity (one gastric haemorrhage and one interstitial pneumonitis in the single-agent arm, and one folliculitis in the doublet arm). 
TABLE 2 Reasons for discontinuing second-line therapy (L2) in both arms

\begin{tabular}{lccc} 
Reason for stopping L2 & All patients & Monotherapy arm & Doublet chemotherapy arm $^{+}$ \\
\hline Death & $49(16.9)$ & $26(18.1)$ & $23(15.6)$ \\
$\quad$ Due to cancer & $39(79.6)$ & $22(84.6)$ & $17(73.9)$ \\
Intercurrent disease & $9(18.4)$ & $4(15.4)$ & $5(81.7)$ \\
Unknown reason & $1(2.04)$ & $0(0)$ & $1(4.35)$ \\
Disease progression & $183(63.1)$ & $92(64.3)$ & $91(61.9)$ \\
Consent withdrawal & $3(1.0)$ & $2(1.4)$ & $1(0.7)$ \\
Excessive toxicity & $28(9.7)$ & $11(7.6)$ & $17(11.6)$ \\
Protocol violation & $2(0.7)$ & 0 & $2(1.4)$ \\
Other & $25(8.6)$ & $12(8.3)$ & $13(8.8)$ \\
General condition deterioration & $15(5)$ & $6(4.1)$ & $9(6.3)$ \\
Patient refusal & $6(2)$ & $3(2.1)$ & $3(2.1)$ \\
Other & $4(1.5)$ & $3(2.1)$ & $1(0.7)$ \\
\hline
\end{tabular}

Data are presented as $n(\%)$ or $n .^{*}: n=290 ;{ }^{\circ}: n=143 ;^{+}: n=147$.

\section{Discussion}

In our study, $292(64.7 \%)$ out of 451 patients were eligible to receive the assigned second-line therapy. This figure compares favourably to that of $49 \%$ reported for a cohort of 406 unselected patients [13], but less favourably with the maintenance phase III trial study conducted by our intergroup in which $>77 \%$ of the randomised patients (aged 18-70 years, median 56.4-59.8 years) received the predefined second-line therapy [14]. These patients were, however, 1) younger (maximum age for inclusion 75 years) and 2) highly selected (all were without disease progression after induction treatment). In our study, the strategy, as in the cohort of unselected patients [13], differed because second-line therapy was proposed when disease progression occurred, regardless of whether it was during or after the induction phase. As reported in a previous study, the likelihood of receiving second-line chemotherapy was strongly determined by performance status [15]. Furthermore, in our study, several geriatric indexes had a significant influence on being selected to receive second-line chemotherapy (MMS and ADL), which, to the best of our knowledge, has not been described elsewhere. Median duration of treatment was $\sim 2$ months, with no significant difference documented between the initial arms (monotherapy or carboplatin doublet). This duration is similar to that of the BR21 trial. Moreover, the median overall survival of 6.8 (5.0-8.3) months recorded in our study patients who were initially randomised to the doublet arm was similar to that observed in the BR21 study for those treated with erlotinib (6.7 months) [10]. In both instances, erlotinib was administered following a platinum-based doublet, regardless of EGFR mutational status. Median survival of our study patients previously treated with monotherapy was inferior to that observed when they first received the carboplatinweekly paclitaxel doublet. This difference, however, was not statistically significant. Moreover, the randomisation arm was not a significant prognostic factor for overall survival under erlotinib treatment. The trend observed toward a longer survival under erlotinib for the doublet-arm patients might be explained by a significant higher response rate and a longer time to progression under first-line therapy in

FIGURE 3 Overall survival with erlotinib according to treatment arm. Hazard ratio $0.81,95 \%$ CI $0.64-1.03$; $\mathrm{p}=0.0897$.

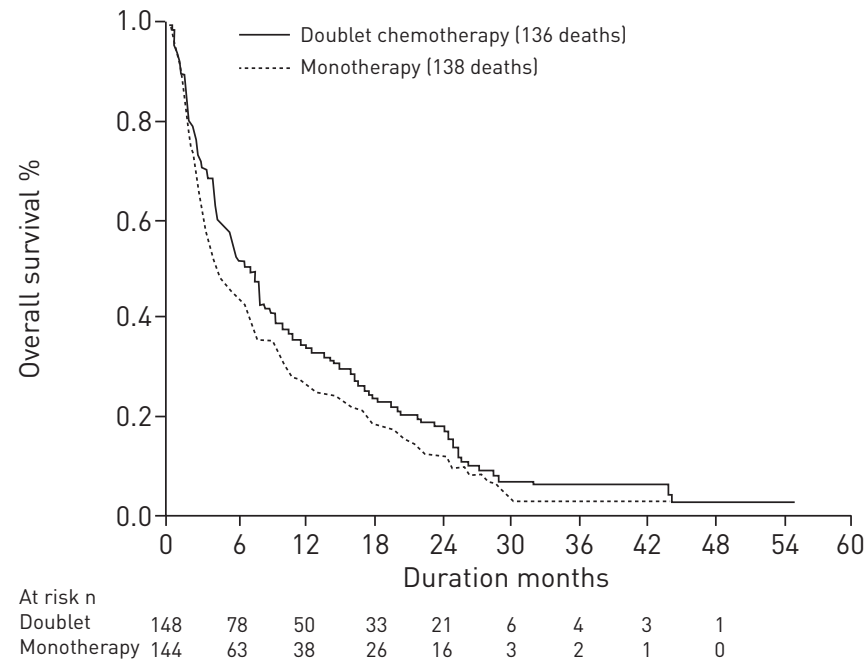


TABLE 3 Univariate and multivariate analyses of overall survival under second-line therapy

\begin{tabular}{|c|c|c|c|c|c|}
\hline & \multirow[t]{2}{*}{ Patients n } & \multicolumn{2}{|c|}{ Univariate $^{\#}$} & \multicolumn{2}{|c|}{ Multivariate } \\
\hline & & $\operatorname{HR}(95 \% \mathrm{CI})$ & p-value & $\operatorname{HR}(95 \% \mathrm{CI})$ & p-value \\
\hline \multicolumn{6}{|l|}{ Treatment arm } \\
\hline Doublet chemotherapy & 148 & $0.81(0.64-1.03)$ & 0.0897 & & \\
\hline Monotherapy & 144 & 1 & & & \\
\hline \multicolumn{6}{|l|}{ Sex } \\
\hline Male & 210 & 1 & & & \\
\hline Female & 82 & $0.67(0.51-0.88)$ & 0.004 & & \\
\hline \multicolumn{6}{|l|}{ Age years } \\
\hline$\leqslant 80$ & 217 & $0.92(0.70-1.20)$ & 0.530 & & \\
\hline \multirow{2}{*}{\multicolumn{6}{|c|}{ Performance status }} \\
\hline & & & & & \\
\hline $0-1$ & 234 & $0.56(0.42-0.76)$ & 0.0002 & $0.63(0.47-0.86)$ & 0.0034 \\
\hline 2 & 58 & 1 & & 1 & \\
\hline \multicolumn{6}{|l|}{ Stage } \\
\hline IIIA-IIIB & 47 & $0.82(0.59-1.13)$ & 0.218 & & \\
\hline \multicolumn{5}{|l|}{ Histology } & \\
\hline Squamous or other & 142 & 1 & & 1 & \\
\hline $\begin{array}{l}\text { Adenocarcinoma } \\
\text { Smoking status }\end{array}$ & 150 & $0.53(0.42-0.68)$ & $<0.0001$ & $0.68(0.52-0.88)$ & 0.0039 \\
\hline Never smoked & 68 & $0.50(0.37-0.67)$ & $<0.0001$ & $0.62(0.45-0.85)$ & 0.0034 \\
\hline $\begin{array}{l}\text { Ever smoked } \\
\text { MMS examination }\end{array}$ & 224 & 1 & & 1 & \\
\hline$\leqslant 23$ & 34 & 1 & & & \\
\hline$>23$ & 250 & $0.91(0.63-1.31)$ & 0.598 & & \\
\hline \multicolumn{6}{|l|}{ ADL score } \\
\hline$<6$ & 42 & 1 & & & \\
\hline 6 & 239 & $0.82(0.59-1.15)$ & 0.252 & & \\
\hline \multicolumn{6}{|c|}{$0.02(0.07=1.10)$} \\
\hline$\leqslant 2$ & 226 & 0.79 (0.59-1.05) & 0.099 & & \\
\hline$>2$ & 66 & 1 & & & \\
\hline \multicolumn{6}{|l|}{ BMI $\mathrm{kg} \cdot \mathrm{m}^{-2}$} \\
\hline$\leqslant 20$ & 32 & 1 & & & \\
\hline 20 to $\leqslant 26$ & 156 & $0.91(0.62-1.35)$ & 0.651 & & \\
\hline$>26$ to $\leqslant 30$ & 70 & $0.75(0.49-1.15)$ & 0.180 & & \\
\hline$>30$ & 34 & $0.88(0.53-1.45)$ & 0.606 & & \\
\hline \multicolumn{6}{|l|}{$\begin{array}{l}\text { Weight loss before } \\
\text { randomisation \% }\end{array}$} \\
\hline$\leqslant 5$ & 144 & $0.66(0.52-0.84)$ & 0.0008 & $0.76(0.60-0.98)$ & 0.0337 \\
\hline$>5$ & 144 & 1 & & 1 & \\
\hline
\end{tabular}

HR: hazard ratio; MMS: mini-mental state; ADL: activities of daily living questionnaire; CCl: Charlson's comorbidity index; BMI: body mass index. ${ }^{\#}: \mathrm{n}=292 ;{ }^{\circ}: \mathrm{n}=288$.

the doublet arm [6], possibly providing a better general condition at the beginning of erlotinib. As a matter of fact, even though data were missing in $30-40 \%$ of the patients, there still was a trend toward a better performance status and a significantly higher BMI in patients initially included in the doublet arm, but no difference in weight loss between randomisation and the beginning of erlotinib (online supplementary tables S2 and S3). Multivariate analysis of survival revealed that initial performance status (before induction treatment) remained a strong prognostic factor. Other independent favourable prognostic factors were never-smoker status, adenocarcinoma histology and no significant weight loss prior to induction treatment. The interaction between smoking status and histology may show that these clinical features do have an impact on erlotinib efficacy, as could be expected. In smokers with adenocarcinoma, however, at least onethird of patients likely exhibit KRAS mutations [16], which precludes any efficacy of TKIs. As analyses of EGFR and KRAS mutations were not routinely performed in France when we initiated this study, we cannot retrospectively verify such hypotheses.

Grade 3-4 toxicity due to erlotinib was somewhat lower than that observed in the BR21 study [11], in which grade 3-4 toxicity was observed in 35\% of elderly patients versus $18 \%$ of their younger counterparts $(\mathrm{p}<0.001)$. In our study, only $20.5 \%$ of patients experienced grade $3-4$ toxicity, and treatment was discontinued due to excessive toxicity in $9.7 \%$ versus $12 \%$ in the BR2 1 study. 

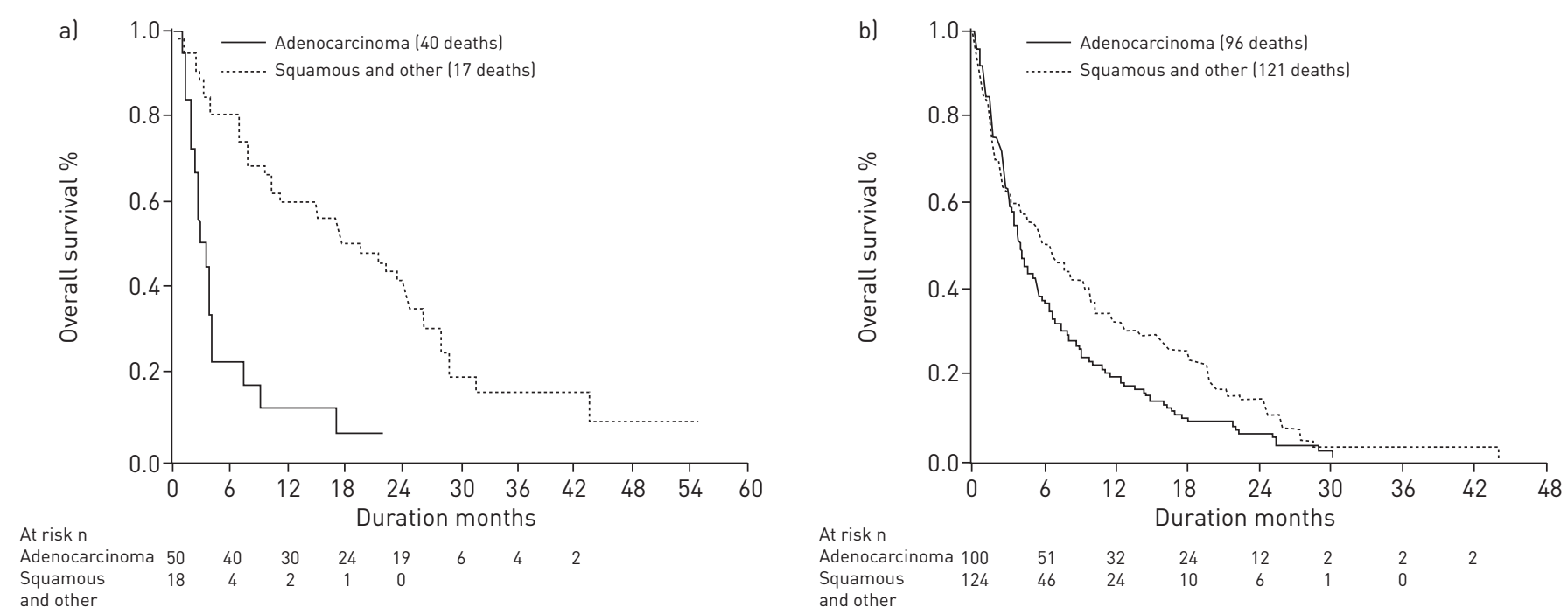

FIGURE 4 Overall survival with erlotinib according to histology. a) Never-smokers. Crude hazard ratio (HR) (95\% CI) 0.23 (0.12-0.44), p $<0.0001$. HR adjusted for performance status and weight loss 0.23 (CI 0.12-0.45), p<0.0001. b) Ever-smokers. Crude HR 0.74 (0.56-0.97), p=0.0300. Adjusted HR 0.80 (0.60-1.05), $\mathrm{p}=0.1091$. Interaction test, $\mathrm{p}=0.0013$. Adjusted interaction test, $\mathrm{p}=0.0011$.

Our study did not examine the role of maintenance therapy. In the Sequential Tarceva in Unresectable NSCLC (SATURN) study, which evaluated the value of maintenance erlotinib versus placebo using a randomised design, following four induction cycles with a platinum-based doublet, regardless of EGFR mutational status, maintenance erlotinib therapy proved to be of value in terms of overall survival for patients with stabilised disease at the end of induction therapy [17]. Through an exploratory subgroup

TABLE 4 Grade 3-4 toxic effects in patients who received at least one dose of second-line therapy

\begin{tabular}{|c|c|c|c|c|}
\hline & \multicolumn{2}{|c|}{ Monotherapy arm ${ }^{\#}$} & \multicolumn{2}{|c|}{ Doublet chemotherapy arm } \\
\hline & Grade 3 & Grade 4 & Grade 3 & Grade 4 \\
\hline Subjects & 26 & 2 & 32 & 1 \\
\hline Skin disorders & 15 (58) & & $16(50)$ & 1 \\
\hline Alanine aminotransferase increase & 0 & & $1(3)$ & \\
\hline Anorexia & $8(31)$ & & $2(6)$ & \\
\hline Asthenia & $7(27)$ & & $5(16)$ & \\
\hline Conjunctivitis & $1(4)$ & & 1 (3) & \\
\hline Depression & 0 & & $1(3)$ & \\
\hline Diarrhoea & $3(12)$ & & $5(16)$ & \\
\hline Limb oedema & 0 & & $1(3)$ & \\
\hline$\gamma$-glutamyltransferase increase & 0 & & $1(3)$ & \\
\hline Gastric haemorrhage & & 1 & & \\
\hline Gastrointestinal disorder & $1(4)$ & & 0 & \\
\hline Hemiplegia & $1(4)$ & & 0 & \\
\hline Haemoglobin decrease & 0 & & $1(3)$ & \\
\hline Interstitial pneumonitis & & 1 & & \\
\hline Mouth irritation & 2 (8) & & $1(3)$ & \\
\hline Nail infection & 0 & & $1(3)$ & \\
\hline Nausea & $1(4)$ & & $1(3)$ & \\
\hline Rectal haemorrhage & 0 & & $1(3)$ & \\
\hline Reduced general condition & 0 & & $2(6)$ & \\
\hline Sensory neuropathy & 0 & & $1(3)$ & \\
\hline Subcutaneous emphysema & 0 & & $1(3)$ & \\
\hline Vomiting & 0 & & $1(3)$ & \\
\hline
\end{tabular}

Data are presented as $n$ or $n(\%) .{ }^{*}: n=28 ;{ }^{\circledR}: n=32$. 
analysis, however, no benefit was found for patients aged $\geqslant 65$ years. One element that is missing from the SATURN study is the type of second-line therapy assigned to the placebo group. It would have been interesting to find out if, at least in a subgroup analysis, patients receiving delayed erlotinib (in the placebo arm) fared similarly to patients in the maintenance arm.

In conclusion, our study confirmed the feasibility of second-line erlotinib therapy in elderly patients, with an acceptable grade 3-4 toxicity rate. Although our study was not designed to reconfirm the survival benefit induced by this second-line therapy, we are now in the position to confirm the prognostic role of initial performance status, smoking status, initial weight loss and histology in elderly patients receiving second-line therapy. However, although we provide original data on the efficacy of geriatric indexes used in this study (MMS and ADL), in predicting the probability of receiving second-line erlotinib, these indexes did, in fact, fail to significantly influence the probability of survival.

\section{Acknowledgements}

We thank the following investigators for their generous contributions: P. Masson (Centre Hospitalier (CH), Cholet, France), J-P. Duhamel (Clinique le Petit Colmoulins, Harfleur, France), Y. Martinet (Centre Hospitalier Universitaire (CHU) Brabois, Vandoeuvre-Les-Nancy, France), C. Vidal (CH, Blois, France), B. Gentil-Lepecq (CH, Bourgoin-Jailleu, France), Pierre Bombaron ( $\mathrm{CH}$, Mulhouse, France), A. Prevost (Institut Jean Godinot, Reims, France), D. Coëtmeur (CH, Saint-Brieuc, France), C. Galichet (CH, Saverne, France), S. Labrune (APHP, Hôpital Amboise Paré, Boulogne, France), M. Zaegel ( $\mathrm{CH}$, Chartres, France), P. Bonnefoy ( $\mathrm{CH}$, Jonzac, France), J-M. Vannetzel (Institut d'Oncologie Hartmann, Levallois, France), N. Paillot (CH, Metz, France), J-L. Pujol (CHU, Montpellier, France), J. Meunier (CH, Orléans, France), B. Stach (Clinique Teissier, Valenciennes, France), S. Schneider (CH, Bayonne, France), D. Braun (CH, Briey, France), L. Gautier-Felizot (CH, Dax, France), F. Lebargy (CHU, Reims, France), P. Nouyrigat (CH Intercommunal, Toulon, France), M. Farny (CH, Cahors, France), C. Sarda (CH Intercommunal de Castres-Mazamet, Castres, France), F. Martin (CH, Compiègne, France), J. Hermann (Hôpital Belle-Isle, Metz, France), G. Fraboulet (CH, Pontoise, France), P. Richard (CH, Saint-Omer, France), S. Friard (APHP, Hôpital Foch, Suresnes, France), F. Goutorbe (CH, Béziers, France), A. Levy ( $\mathrm{CH}$, Bourges, France), Y. Duval ( $\mathrm{CH}$, Cannes, France), M. Angebault ( $\mathrm{CH}$, Chevilly Larue, France), P. Charvolin ( $\mathrm{CH}$, Senlis, France), M. Roa (CH Intercommunal de Fréjus-Saint Raphaël, Fréjus, France), M. Vincent (Hôpital Saint-Joseph Saint-Luc, Lyon, France), S. Larive (CH, Mâcon, France), W. Jacot (Clinique Val d'Aurelle Paule Lamarque, Montpellier, France), M. Boutemy (CH, Saint-Quentin, France) and N. Le Flour (CH Intercommunal, Villeneuve Saint-Georges, France).

We would also like to thank M.P. Lebitasy and Q. Tran (Intergroupe Francophone de Cancérologie Thoracique (IFCT), Paris, France) for their considerable administrative help, and E. Amour and R. Rouveau (also IFCT) for performing data quality checks at the sites. We are also grateful to G. Cremer (Cremer Consulting, Strasbourg, France) who helped to improve the written English of this publication.

\section{References}

1 Quoix E, Monnet I, Scheid P, et al. IFCT 02-02: la prise en charge du cancer bronchique chez les patients âgés de 70 ans et plus en France [Management and outcome of French elderly patients with lung cancer: an IFCT survey]. Rev Mal Respir 2010; 27: 421-430.

2 Pallis AG, Gridelli C, Van Meerbeeck JP, et al. EORTC Elderly Task Force and Lung Cancer Group and International Society for Geriatric Oncology (SIOG) experts' opinion for the treatment of non-small-cell lung cancer in an elderly population. Ann Oncol 2010; 21: 692-706.

3 Belani CP, Fossella F. Elderly subgroup analysis of a randomized phase III study of docetaxel plus platinum combinations versus vinorelbine plus cisplatin for first-line treatment of advanced nonsmall cell lung carcinoma (TAX 326). Cancer 2005; 104: 2766-2774.

4 Lilenbaum RC, Herndon JE 2nd, List MA, et al. Single-agent versus combination chemotherapy in advanced nonsmall-cell lung cancer: the cancer and leukemia group B (study 9730). J Clin Oncol 2005; 23: 190-196.

5 Ansari RH, Socinski MA, Edelman MJ, et al. A retrospective analysis of outcomes by age in a three-arm phase III trial of gemcitabine in combination with carboplatin or paclitaxel $v s$. paclitaxel plus carboplatin for advanced nonsmall cell lung cancer. Crit Rev Oncol Hematol 2011; 78: 162-171.

6 Quoix E, Zalcman G, Oster JP, et al. Carboplatin and weekly paclitaxel doublet chemotherapy compared with monotherapy in elderly patients with advanced non-small-cell lung cancer: IFCT-0501 randomised, phase 3 trial. Lancet 2011; 378: 1079-1088.

7 Ganti AK, de Shazo M, Weir AB 3rd, et al. Treatment of non-small cell lung cancer in the older patient. J Natl Compr Canc Netw 2012; 10: 230-239.

8 Shepherd FA, Dancey J, Ramlau R, et al. Prospective randomized trial of docetaxel versus best supportive care in patients with non-small-cell lung cancer previously treated with platinum-based chemotherapy. J Clin Oncol 2000; 18: 2095-2103.

9 Hanna N, Shepherd FA, Fossella FV, et al. Randomized phase III trial of pemetrexed versus docetaxel in patients with non-small-cell lung cancer previously treated with chemotherapy. J Clin Oncol 2004; 22: 1589-1597.

10 Shepherd FA, Rodrigues Pereira J, Ciuleanu T, et al. Erlotinib in previously treated non-small-cell lung cancer. N Engl J Med 2005; 353: 123-132.

11 Wheatley-Price P, Ding K, Seymour L, et al. Erlotinib for advanced non-small-cell lung cancer in the elderly: an analysis of the National Cancer Institute of Canada Clinical Trials Group Study BR.21. J Clin Oncol 2008; 26: 2350-2357.

12 Miller AB, Hoogstraten B, Staquet M, et al. Reporting results of cancer treatment. Cancer 1981; 47: 207-214.

13 Gerber DE, Rasco DW, Le P, et al. Predictors and impact of second-line chemotherapy for advanced non-small cell lung cancer in the United States: real-world considerations for maintenance therapy. J Thorac Oncol 2011; 6: 365-371. 
14 Perol M, Chouaid C, Milleron BJ. Maintenance with either gemcitabiene or erlotinib versus observation with predefined second-line tretament after cisplatin-gemcitabine induction chemotherapy in advanced NSCLC??: IFCT-GFPC 0502 phase III study. J Clin Oncol, 28: 540S.

15 Sun JM, Park JO, Won YW, et al. Who are less likely to receive subsequent chemotherapy beyond first-line therapy for advanced non-small cell lung cancer? Implications for selection of patients for maintenance therapy. $J$ Thorac Oncol 2010; 5: 540-545.

16 Johnson JL, Pillai S, Chellappan SP. Genetic and biochemical alterations in non-small cell lung cancer. Biochem Res Int 2012; 2012: 940405.

17 Coudert B, Ciuleanu T, Park K, et al. Survival benefit with erlotinib maintenance therapy in patients with advanced non-small-cell lung cancer (NSCLC) according to response to first-line chemotherapy. Ann Oncol 2012; 23: 388-394. 